\title{
Toward New High Temperature Reference Materials for Calorimetry and Thermal Analysis
}

\author{
R. Razouk ${ }^{1}$, B. Hay ${ }^{1, a}$, M. Himbert ${ }^{1}$ \\ ${ }^{1}$ Laboratoire Commun de Métrologie LNE-Cnam (LCM), Laboratoire National de Métrologie et d'Essais, Scientific and \\ Industrial Metrology Centre, 78197 Trappes, France
}

\begin{abstract}
The French National Metrology Laboratory LNE-LCM has developed a high temperature reference facility for accurate measurements of the specific heat capacity and of the enthalpy of fusion of materials over the temperature range $\left[23{ }^{\circ} \mathrm{C}, 1000{ }^{\circ} \mathrm{C}\right]$. The metrological approach was to modify a commercial Calvet calorimeter in order to lower the uncertainty of measurement and to insure the metrological traceability of the measurements to the SI units, in particular by designing a new calibration system. The enthalpies of fusion of pure metals (indium, tin and silver) and of a binary alloy Ag-28Cu have been measured. The results obtained on the three pure metallic materials are in very good agreement with data obtained by other National Metrology Institutes (NMIs) using adiabatic calorimetry.
\end{abstract}

\section{Introduction}

Differential Scanning Calorimeters (DSCs) are often used to determine the specific heat or the enthalpy of phase transitions of materials. The calibration of the DSC is a fundamental step enabling to ensure the reliability and the accuracy of the measurements of these caloric quantities. It requires the establishment of a relationship between the value indicated by the measuring instrument and the true value. The heat calibration is performed, for instance, by generating a known quantity of energy within the calorimeter and by measuring its response as a function of time.

The temperature, heat and heat flow rate calibrations of this type of analytical instrument are generally done according to the recommendations of international standards [1], through the melting of pure metals defining the fixed points of the international temperature scale of 1990 (ITS90) [2]. These reference materials are gallium, indium, tin, zinc and aluminium, and their enthalpy of fusion is usually accurately measured by adiabatic calorimetry [3, 4]. The International Union of Pure and Applied Chemistry (IUPAC) published in 2006 [5] updated values of recommended reference materials (RMs) for the calibration of DSCs. There is a lack of certified reference materials (CRMs) above $660{ }^{\circ} \mathrm{C}$, while the operating range of some calorimeters exceeds $1000{ }^{\circ} \mathrm{C}$.

For this reason, and according to its experience in the field of calorimetry [6-10], LNE-LCM developed a high temperature reference facility. A commercial heat conduction differential Calvet calorimeter was modified [11] and new procedures for calibration and measurement were implemented. This apparatus enables to perform accurate measurements of specific heat and enthalpy of fusion up to $1000{ }^{\circ} \mathrm{C}$ that are directly traceable to the international system of units (SI), with uncertainties relevant to the objective of the certification of reference materials. The key point of this work was the development of a new in-situ calibration system integrated into the calorimeter. It can be used to perform the heat calibration of the calorimeter by electrical substitution (Joule effect) and the enthalpy measurements without modification of the apparatus, so that the experimental conditions during both steps remain unchanged. The performances of this new calibration system as well as the metrological features (repeatability, linearity...) of the calorimeter were evaluated by investigating the impact of some influence parameters (level of energy, temperature, dissipation time) on the determination of the sensitivity factor of its thermopiles (the results of this metrological characterisation were presented in a previous paper [12]). This reference facility, and the procedures of calibration and measurement associated, have been then applied to the determination of the enthalpies of fusion of indium, tin, silver, and of an eutectic alloy $(\mathrm{Ag}-28 \mathrm{Cu})$.

This paper gives a brief description of the calorimeter, of the calibration system, and of the procedures of calibration and measurement. The results obtained for the enthalpy of fusion of three pure metallic materials and of the eutectic alloy are presented here and discussed in detail.

\footnotetext{
${ }^{\mathrm{a}}$ Corresponding author: bruno.hay@lne.fr
} 


\section{Description of the reference setup}

The measurements of enthalpy of fusion were carried out by using a heat flux Calvet calorimeter type HT1000, manufactured by the French company Sétaram. It is mainly composed by two measuring cells symmetrically placed in a calorimetric block heated by a resistive furnace. Two heat flux sensors (or thermopiles) surround the measuring cells and are connected in opposition. Each sensor is composed of a set of type $S$ thermocouples connected in series. A specimen of the studied material is placed in an alumina crucible located in one of the two symmetric cells. As it undergoes a phase transition, it exchanges heat with the calorimetric block via the thermopiles. The signal $S(t)$ delivered by the thermopiles (given in $\mu \mathrm{V}$ ) is measured as a function of time $t$. Its magnitude is proportional to the difference of the heat flux exchanged by conduction between the cells and the calorimetric block. The integration of this signal over the whole duration of the reaction divided by the sensitivity coefficient Sens of the thermopiles (expressed in $\mu \mathrm{V} \cdot \mathrm{W}^{-1}$ ) is equal to the energy released or absorbed in the cell. A type $\mathrm{S}$ thermocouple located in the calorimetric block measures the mean temperature of the measuring cells.

A high temperature calibration system was especially designed. It is constituted by a resistance wire wound around the crucible containing the material specimen. This system stays inside the calorimeter during both calibration and measurement phases, in order to have similar experimental conditions. A strictly identical calibration system is put in each alumina tube to keep the thermal symmetry between both cells.

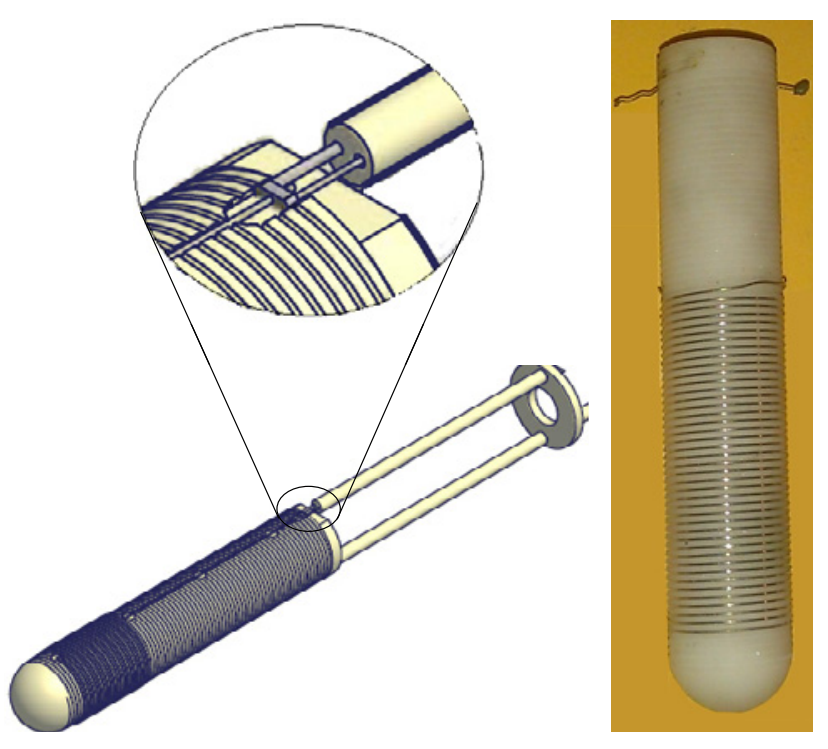

Figure 1. Instrumented calibration crucible

A scheme and a picture of this instrumented calibration crucible are shown in Figure 1. An acquisition system with calibrated devices has been assembled in order to perform accurate and traceable measurements of the energy released in the calorimeter during the calibration process, and of the electromotive force (EMF) delivered by the two thermopiles in both calibration and enthalpy measurement steps. More information on this calibration system has already been published [12]. Figure 2 presents a schematic diagram of the arrangement of the calorimeter with the calibration crucibles and the associated acquisition system.

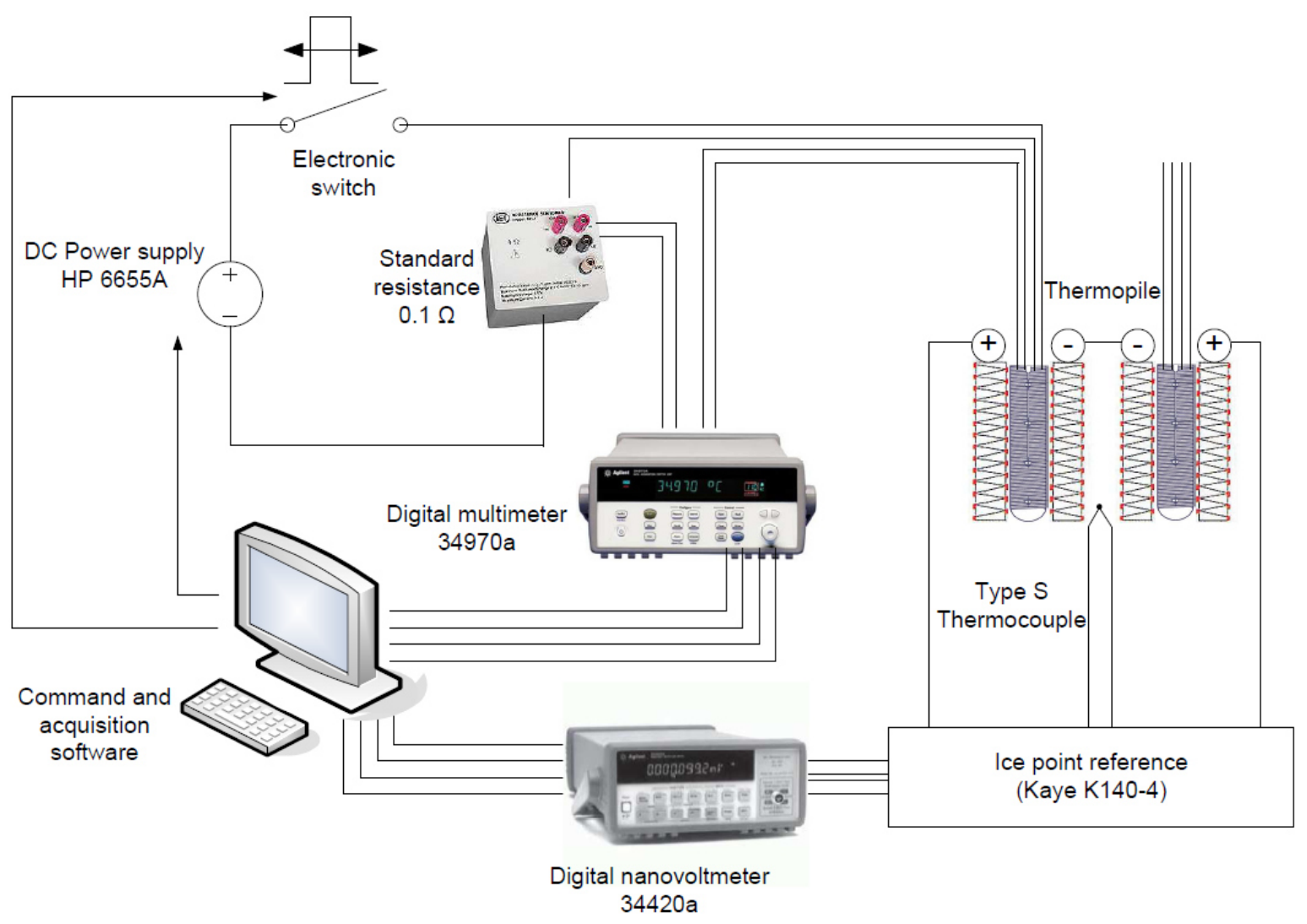

Figure 2. Electrical diagram of the reference facility. 


\section{Calibration and measurement procedures}

The enthalpy of fusion is measured by performing the calibration of the calorimeter and the enthalpy measurement during the same heating run. The calibration crucible containing the studied specimen is introduced inside one measuring cell of the calorimeter, which is maintained at a constant temperature. The calorimeter is then heated at a constant rate of $15 \mathrm{mK}$ per minute, and two energy dissipations $E_{1}$ and $E_{2}$ are generated by Joule effect before and after the fusion of the specimen at temperatures $T_{1}$ and $T_{2}$ respectively. Figure 2 illustrates this procedure in the case of the measurement of the enthalpy of fusion of tin, with two exothermic peaks corresponding to the electrical dissipations that surround the endothermic peak of fusion.

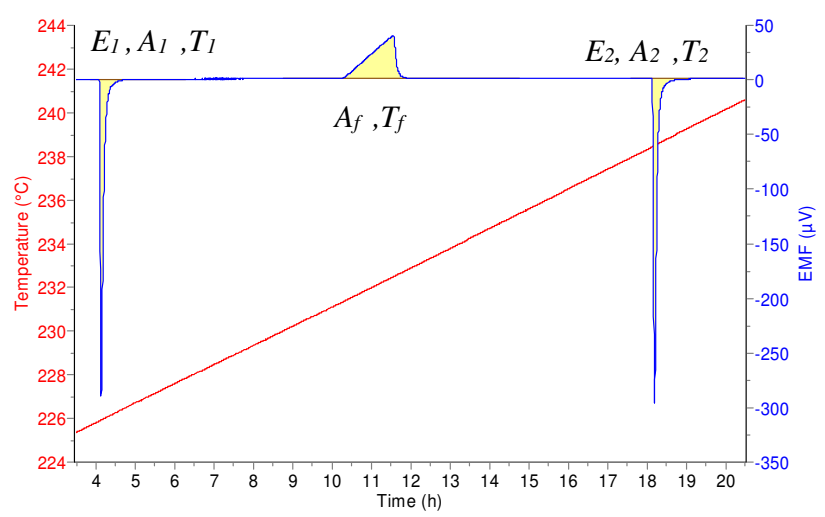

Figure 3. Temperature and electromotive force delivered by the thermopiles versus time.

$T_{1}, T_{2}$ : Temperatures before and after the fusion,

$T_{f}:$ Onset temperature of the peak of fusion, $A_{f}$ : Fusion peak area,

$A_{1}, A_{2}$ : Areas corresponding to the electrical energies $E_{1}, E_{2}$

The sensitivities $\operatorname{Sens}_{1}$ and $\operatorname{Sens}_{2}$ (in $\mu \mathrm{V} \cdot \mathrm{W}^{-1}$ ) of the calorimeter at temperatures $T_{1}$ and $T_{2}$ are estimated as the ratio of the areas $A_{l}$ and $A_{2}$ (in $\mu \mathrm{V} \cdot \mathrm{s}$ ) to the dissipated electrical energies $E_{l}$ and $E_{2}$ (in $\mathrm{J}$ ). The energies $E$ are the integration of the electrical power $P(t)$ over the dissipation time $t_{d i s}$ where $P(t)$ is calculated from the measurements of the voltage drops $U_{\text {heat }}(t)$ and $U_{\text {ref }}(t)$ across the calibration crucible and across the standard resistance of value $R_{s}$.

$$
E=\int_{0}^{t_{d i s}} P(t) d t \approx \frac{\overline{U_{\text {heat }}} \cdot \overline{U_{r e f}}}{R_{s}} t_{d i s}
$$

The areas $A$ between the measured curve $S(t)$ and the virtual baseline $S_{0}(t)$ are calculated by numerical integration. In the case of an electrical calibration (areas $A_{1}$ and $A_{2}$ ), the baseline $S_{0}(t)$ is interpolated between the start and the end of the peak by a straight line. For a fusion (area $A_{f}$ ), the interpolated baseline is constructed by an iterative method on the basis of the initial and final baselines (respectively baselines before and after the peak) and of the degree of conversion of the reaction [13].

The sensitivity $\operatorname{Sens}_{f}$ of the calorimeter at the "onset temperature" of fusion $T_{f}$ is interpolated linearly from the values of Sens 1 and Sens 2 . This temperature is defined by the intersection of the interpolated baseline and the tangent drawn at point of inflection of the rising side of the peak. The assumption of the linearity of the sensitivity versus temperature between $T_{1}$ and $T_{2}$ was previously verified [12].

This procedure directly takes into account the temperature dependence of the thermopile sensitivity and keeps the calibration and measurement conditions strictly the same. It does not require an accurate temperature calibration of the apparatus. The enthalpy of fusion $\Delta H_{f}$ (expressed in $\mathrm{J}^{-1} \mathrm{~g}^{-1}$ ) of a specimen of mass $m$ is calculated by equation 2 .

$$
\Delta H_{f}=\frac{1}{m} \cdot \frac{A_{f}}{\operatorname{Sens}_{f}}
$$

\section{Measurements of enthalpy of fusion}

The enthalpies of fusion of indium, tin, silver and the eutectic alloy $\mathrm{Ag}-28 \mathrm{Cu}$ have been measured as described above. Indium and tin are the most frequently used reference materials for enthalpy and temperature calibrations of DSCs. For each tested specimen, measurements were performed for at least five successive heating runs. After each run, the calorimetric block is cooled to a temperature lower than the temperature of fusion of the specimen, the calibration system is removed from the calorimeter, and then reintroduced. This procedure yields information on the repeatability of measurements.

The results obtained for the four materials are presented for specimens of various masses in the following subsections, with in particular: the values of the individual measurements of enthalpy of fusion, the corresponding mean value (MV) and relative standard deviation (SD).

\subsection{Indium}

The enthalpy of fusion of a high purity $5 \mathrm{~N}$ indium (from Goodfellow) was measured for two specimens with masses of $108 \mathrm{mg}$ and $521 \mathrm{mg}$. Results are summarized in tables 1 and 2 .

Table 1. Enthalpy of fusion of indium - mass $=107.78 \mathrm{mg}$

\begin{tabular}{ccccc}
\hline \hline Test & $\begin{array}{c}\text { Temp. } \\
\left({ }^{\circ} \mathbf{C}\right)\end{array}$ & $\begin{array}{c}\boldsymbol{A}_{f} \\
(\boldsymbol{\mu V} \cdot \mathbf{s})\end{array}$ & $\begin{array}{c}\boldsymbol{S e n s}_{f} \\
\left(\boldsymbol{\mu} \mathbf{V} \cdot \mathbf{W}^{-1}\right)\end{array}$ & $\begin{array}{c}\Delta \boldsymbol{H}_{f} \\
\left(\mathbf{J}^{-1}\right)\end{array}$ \\
\hline 1 & 156.26 & 8304 & 2694.0 & 28.60 \\
2 & 156.25 & 8396 & 2722.6 & 28.61 \\
3 & 156.28 & 8386 & 2719.0 & 28.62 \\
4 & 156.21 & 8364 & 2708.2 & 28.67 \\
5 & 156.25 & 8388 & 2724.4 & 28.58 \\
6 & 156.24 & 8435 & 2732.9 & 28.65 \\
\hline MV & 156.25 & 8379 & 2716.8 & 28.62 \\
SD (\%) & 0.01 & 0.52 & 0.51 & 0.12 \\
\hline \hline
\end{tabular}


Table 2. Enthalpy of fusion of indium - mass $=521.09 \mathrm{mg}$

\begin{tabular}{ccccc}
\hline \hline Test & $\begin{array}{c}\text { Temp. } \\
\left({ }^{\circ} \mathbf{C}\right)\end{array}$ & $\begin{array}{c}\boldsymbol{A}_{f} \\
(\boldsymbol{\mu V} \cdot \mathbf{s})\end{array}$ & $\begin{array}{c}\text { Sensf } \\
\left(\boldsymbol{\mu} \mathbf{V} \cdot \mathbf{W}^{-1}\right)\end{array}$ & $\begin{array}{c}\Delta \boldsymbol{H}_{f} \\
\left(\mathbf{J . g}^{-1}\right)\end{array}$ \\
\hline 1 & 156.33 & 40718 & 2728.9 & 28.63 \\
2 & 156.25 & 40629 & 2722.6 & 28.65 \\
3 & 156.32 & 40487 & 2714.6 & 28.62 \\
4 & 156.28 & 40548 & 2715.4 & 28.66 \\
5 & 156.25 & 40415 & 2709.5 & 28.63 \\
6 & 156.25 & 40357 & 2707.6 & 28.60 \\
7 & 156.26 & 40410 & 2711.2 & 28.60 \\
\hline MV & 156.28 & 40509 & 2715.7 & 28.63 \\
\hline SD (\%) & 0.02 & 0.32 & 0.28 & 0.08 \\
\hline \hline
\end{tabular}

The relative standard deviation SD for the repeated measurements of enthalpy of fusion performed on the two specimens are about $0.10 \%$. The deviation between the two mean values MV is $0.01 \mathrm{J.g}^{-1}$, while the masses of the specimens differ by a factor of 5 . This deviation is negligible compared to the relative expanded uncertainty $(\mathrm{k}=2)$, that was evaluated in a first estimation according to the ISO/BIPM "Guide to the expression of uncertainty

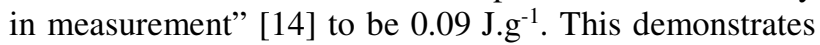
that the method proposed here to measure the enthalpy of fusion $\Delta H_{f}$ gives similar results whatever the mass of the tested specimen, and can be therefore considered not sensitive to this parameter.

Table 3. Indium - Comparison with results from other laboratories

\begin{tabular}{cccc}
\hline Laboratory & Material & $\begin{array}{c}\text { Enthalpy } \\
\left(\mathbf{J . g}^{-1}\right)\end{array}$ & $\begin{array}{c}\text { Uncert. (k=2) } \\
\left(\mathbf{J . g}^{-1}\right)\end{array}$ \\
\hline NIST & SRM2232 & 28.51 & 0.19 \\
LGC & LGC2601 & 28.71 & 0.08 \\
PTB & ZRM 31402 & 28.64 & 0.11 \\
LNE & 5N Goodfellow & 28.63 & 0.09 \\
\hline \hline
\end{tabular}

The mean value of the enthalpy of fusion calculated from the measurements performed at LNE on the two specimens of indium is $28.63 \pm 0.09 \mathrm{J.g}^{-1}$. Table 3 presents a comparison between the values of enthalpy of fusion of pure indium determined by LNE and data given in the certificates of reference materials provided by three other laboratories: NIST (National Institute of Standards and Technology, USA), LGC (Laboratory of the
Government Chemist, UK) and PTB (Physikalisch Technische Bundesanstalt, Germany). Figure 4 plots the enthalpy of fusion of indium as a function of laboratories. The values are given along with their uncertainty bars estimated by each laboratory with a coverage factor $k=2$. Data from LNE for pure indium shows a good agreement with the results obtained by NIST, LGC and PTB.

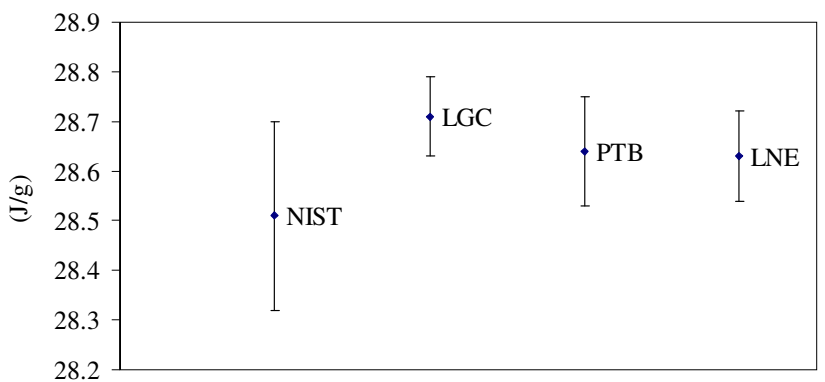

Figure 4. Enthalpy of fusion of indium versus laboratories.

\subsection{Tin}

The enthalpy of fusion of pure tin $(6 \mathrm{~N}$ from Billiton Arnhem) was measured on two specimens of $305 \mathrm{mg}$ and $600 \mathrm{mg}$. Repeated measurements were also performed by moving the specimen of $305 \mathrm{mg}$ from one measuring cell to the other one. Results are presented in tables 4 to 6 .

The results for the three series of five consecutive measurements are in good agreement. They exhibit the same relative standard deviations $(0.03 \%$ to $0.05 \%)$ and a difference between the three mean values of about $0.01 \%$. The equivalence of results obtained by performing the measurement either in one cell of the calorimeter or in the other one, shows that the proposed method is insensitive to the choice of the measuring cell. The mean value of the enthalpy of fusion of tin measured at LNE-LCM is thus $60.23 \pm 0.19{\mathrm{~J} . \mathrm{g}^{-1}}_{(\mathrm{k}=2)}$.

Table 4. Enthalpy of fusion of tin - mass $=600.43 \mathrm{mg}$

\begin{tabular}{ccccc}
\hline \hline Test & $\begin{array}{c}\text { Temp } \\
\left({ }^{\circ} \mathbf{C}\right)\end{array}$ & $\begin{array}{c}\boldsymbol{A}_{f} \\
(\boldsymbol{\mu V} \cdot \mathbf{s})\end{array}$ & $\begin{array}{c}\text { Sens }_{f} \\
\left(\boldsymbol{\mu V} \cdot \mathbf{W}^{-1}\right)\end{array}$ & $\begin{array}{c}\Delta \boldsymbol{H}_{f} \\
\left(\mathbf{J} \cdot \mathrm{g}^{-1}\right)\end{array}$ \\
\hline 1 & 231.22 & 100060 & 2767.0 & 60.23 \\
2 & 231.27 & 100063 & 2767.3 & 60.22 \\
3 & 231.25 & 100299 & 2773.6 & 60.23 \\
4 & 231.28 & 100268 & 2773.6 & 60.21 \\
5 & 231.32 & 100277 & 2771.6 & 60.26 \\
\hline MV & 231.27 & 100193 & 2770.6 & 60.23 \\
SD (\%) & 0.02 & 0.12 & 0.12 & 0.03 \\
\hline \hline
\end{tabular}


Table 5. Enthalpy of fusion of tin - mass $=304.83 \mathrm{mg}-$ cell $\mathrm{n}^{\circ} 1$

\begin{tabular}{ccccc}
\hline \hline Test & $\begin{array}{c}\text { Temp } \\
\left({ }^{\circ} \mathbf{C}\right)\end{array}$ & $\begin{array}{c}\boldsymbol{A}_{f} \\
(\boldsymbol{\mu} \mathbf{V} \cdot \mathbf{s})\end{array}$ & $\begin{array}{c}\boldsymbol{S e n s}_{f} \\
\left(\boldsymbol{\mu} \mathbf{V} \cdot \mathbf{W}^{-1}\right)\end{array}$ & $\begin{array}{c}\Delta \boldsymbol{H}_{f} \\
\left(\mathbf{J . g}^{-1}\right)\end{array}$ \\
\hline 1 & 231.32 & 51067 & 2781.6 & 60.23 \\
2 & 231.34 & 51006 & 2778.4 & 60.23 \\
3 & 231.29 & 51147 & 2785.0 & 60.25 \\
4 & 231.36 & 50810 & 2766.1 & 60.26 \\
5 & 231.41 & 51240 & 2791.6 & 60.21 \\
\hline MV & 231.34 & 51054 & 2780.5 & 60.24 \\
SD (\%) & 0.02 & 0.32 & 0.34 & 0.03 \\
\hline \hline
\end{tabular}

Table 6. Enthalpy of fusion of tin - mass $=304.83 \mathrm{mg}-$ cell $\mathrm{n}^{\circ} 2$

\begin{tabular}{ccccc}
\hline \hline Test & $\begin{array}{c}\text { Temp } \\
\left({ }^{\circ} \mathbf{C}\right)\end{array}$ & $\begin{array}{c}\boldsymbol{A}_{f} \\
(\boldsymbol{\mu} \mathbf{V} \cdot \mathbf{s})\end{array}$ & $\begin{array}{c}\text { Sens }_{f} \\
\left(\boldsymbol{\mu} \mathbf{V} \cdot \mathbf{W}^{-1}\right)\end{array}$ & $\begin{array}{c}\Delta \boldsymbol{H}_{f} \\
\left(\mathbf{J . g}^{-1}\right)\end{array}$ \\
\hline 1 & 231.30 & 51063 & 2778.7 & 60.28 \\
2 & 231.32 & 51010 & 2779.3 & 60.21 \\
3 & 231.33 & 51000 & 2779.0 & 60.20 \\
4 & 231.29 & 51030 & 2778.5 & 60.25 \\
5 & 231.30 & 51102 & 2782.9 & 60.24 \\
\hline MV & 231.31 & 51041 & 2779.7 & 60.24 \\
SD (\%) & 0.01 & 0.08 & 0.07 & 0.05 \\
\hline \hline
\end{tabular}

Table 7 presents a comparison between the value of enthalpy of fusion of tin determined by LNE-LCM and those given in the certificates of reference materials characterized by NIST, LGC and PTB.

Table 7. Tin - Comparison with results from other laboratories

\begin{tabular}{cccc}
\hline Laboratory & Material & $\begin{array}{c}\text { Enthalpy } \\
\left(\mathbf{J . g}^{-1}\right)\end{array}$ & $\begin{array}{c}\text { Uncert. (k=2) } \\
\left(\mathbf{J . g}^{-1}\right)\end{array}$ \\
\hline NIST & SRM 2220 & 60.22 & 0.19 \\
LGC & LGC 2609 & 60.54 & 0.09 \\
PTB & ZRM 31403 & 60.24 & 0.16 \\
LNE & $\begin{array}{c}\text { 6N Billiton } \\
\text { Arnhem }\end{array}$ & 60.23 & 0.19 \\
\hline \hline
\end{tabular}

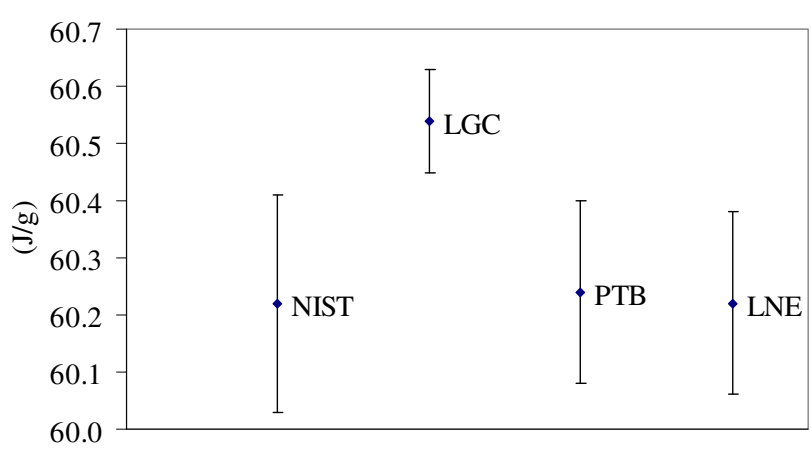

Figure 5. Enthalpy of fusion of tin versus laboratories

In figure 5 is plotted the enthalpy of fusion of tin according to the different laboratories. Values $(k=2)$ show good agreement between the results of the four laboratories, even if the value of LGC is a bit higher than those of the other labs.

\subsection{Silver}

Table 8 presents the results of enthalpy of fusion measurements performed by LNE on a specimen of $481 \mathrm{mg}$ of pure silver ( $5 \mathrm{~N}$ from Goodfellow ).

Table 8. Enthalpy of fusion of silver - mass $=481.16 \mathrm{mg}$

\begin{tabular}{ccccc}
\hline Test & $\begin{array}{c}\text { Temp } \\
\left({ }^{\mathbf{C}}\right)\end{array}$ & $\begin{array}{c}\boldsymbol{A}_{f} \\
(\boldsymbol{\mu V} \cdot \mathbf{s})\end{array}$ & $\begin{array}{c}\text { Sens }_{f} \\
\left(\boldsymbol{\mu V} \cdot \mathbf{W}^{-1}\right)\end{array}$ & $\begin{array}{c}\Delta \boldsymbol{H}_{f} \\
\left(\mathbf{J . g}^{-1}\right)\end{array}$ \\
\hline 1 & 959.45 & 108218 & 2157.7 & 104.1 \\
2 & 959.65 & 108988 & 2157.9 & 104.9 \\
3 & 959.54 & 108445 & 2156.7 & 104.4 \\
4 & 959.11 & 108138 & 2157.6 & 104.1 \\
5 & 959.18 & 108729 & 2158.0 & 104.6 \\
\hline MV & 959.38 & 108504 & 2157.6 & 104.4 \\
SD (\%) & 0.02 & 0.33 & 0.02 & 0.33 \\
\hline \hline
\end{tabular}

The mean value of the LNE-LCM measurements on a specimen of $5 \mathrm{~N}$ silver is equal to $104.4 \pm 1.0 \mathrm{~J} . \mathrm{g}^{-1}$. This result is in accordance with the enthalpy of fusion value $\left(104.61 \pm 2.09 \mathrm{J.g}^{-1}\right)$ recommended by [15], and with data $\left(104.7 \mathrm{J.g}^{-1}\right)$ issued from SGTE (Scientific Group Thermodata Europe) [16].

\subsection{Silver-copper eutectic alloy}

There is no pure metal whose freezing temperature is situated in the interval between the freezing points of aluminium and silver (width almost $300{ }^{\circ} \mathrm{C}$ ). The melting point of the eutectic alloy $\mathrm{Cu} 28.1 \%, \mathrm{Ag} 71.9 \%$ (weight percent) at $779.91{ }^{\circ} \mathrm{C}$ can be a quite relevant auxiliary temperature fixed point [17], but even when realized 
according to the same stringent procedures as for the pure metals, it is reliable to at best $\pm 30 \mathrm{mK}$ [18] compared to $\pm 1 \mathrm{mK}$ for the pure metals [19]. Nevertheless the melting point of this eutectic alloy can be useful for the heat calibration of DSCs if the enthalpy of fusion is accurately determined. There are very few available data about enthalpy of fusion of the binary $\mathrm{Ag}-28 \mathrm{Cu}$ alloy in the literature, and the existing ones differ by a large amount: as an example, Cagran et al. [20] measured the enthalpy of fusion of this eutectic alloy by using a fast pulse-heating technique to $166.4{\mathrm{~J} . \mathrm{g}^{-1}}$, whereas the value issued from SGTE [21] is $137.9{\mathrm{~J} . \mathrm{g}^{-1}}$.

Table 8. Enthalpy of fusion of Ag-28Cu - mass $=184.13 \mathrm{mg}$

\begin{tabular}{ccccc}
\hline \hline Test & $\begin{array}{c}\text { Temp } \\
\left({ }^{\circ} \mathbf{C}\right)\end{array}$ & $\begin{array}{c}\boldsymbol{A}_{f} \\
(\boldsymbol{\mu} \mathbf{V} \cdot \mathbf{s})\end{array}$ & $\begin{array}{c}\text { Sens }_{f} \\
\left(\boldsymbol{\mu} \mathbf{V} \cdot \mathbf{W}^{-1}\right)\end{array}$ & $\begin{array}{c}\Delta \boldsymbol{H}_{f} \\
\left(\mathbf{J . g}^{-1}\right)\end{array}$ \\
\hline 1 & 777.14 & 54690 & 2317.5 & 128.2 \\
2 & 777.07 & 54736 & 2313.1 & 128.5 \\
3 & 777.04 & 54835 & 2307.0 & 129.1 \\
4 & 777.01 & 54528 & 2303.2 & 128.6 \\
5 & 776.97 & 54585 & 2299.7 & 128.9 \\
\hline MV & 777.04 & 54675 & 2308.1 & 128.7 \\
SD (\%) & 0.01 & 0.22 & 0.31 & 0.27 \\
\hline \hline
\end{tabular}

The enthalpy of fusion of this eutectic alloy was measured on a specimen of $184 \mathrm{mg}$. According to the purity analysis of this eutectic alloy produced by Morgan Technical Ceramics, the weight percent composition of this alloy in silver and copper are respectively $71.61 \%$ and $28.39 \%$. The results obtained by LNE-LCM are presented in table 8 . The mean value of five measurements performed successively on a $\mathrm{Ag}-28 \mathrm{Cu}$ specimen is equal to $128.7 \pm 1.2{\mathrm{~J} . \mathrm{g}^{-1}}_{(\mathrm{k}=2)}$.

\section{Conclusion}

A high temperature heat-flux calorimeter has been modified by LNE-LCM in order to enable accurate measurements of specific heat and enthalpy of fusion up to $1000{ }^{\circ} \mathrm{C}$ directly traceable to the SI, with a controlled uncertainty of measurement. An in-situ electrical calibration system has been specifically developed and implemented by applying novel protocols of calibration and measurement.

This metrological facility has been used to measure the enthalpy of fusion of pure indium, tin and silver. The results are in good agreement (relative deviation lower than $0.5 \%$ ) with the values obtained by other National Metrology Institutes on the same materials. The enthalpy of fusion of a $\mathrm{Ag}-\mathrm{Cu}$ eutectic alloy (72 wt $\% \mathrm{Ag}, 28 \mathrm{wt} \% \mathrm{Cu}$ ) was also measured. This material, whose temperature of fusion is about $780{ }^{\circ} \mathrm{C}$, was chosen because it could be a candidate reference material for the calibration of DSCs. The repeatability of 5 consecutive measurements is lower than $0.3 \%$ for the four studied materials, whose melting temperatures cover the whole operating temperature range of the calorimeter. This validation stage has demonstrated the ability of this reference apparatus to perform reliable and repeatable measurement. The next step will be to perform a complete evaluation of the uncertainty of melting enthalpy measurement.

\section{References}

1. ISO 11357-1: 2009

2. H. Preston-Thomas, Metrologia 27, 3 (1990)

3. D.G. Archer and S. Rudtsch, Journal of Chemical \& Engineering Data 48, 1157 (2003)

4. F. Grønvold, Journal of Chemical Thermodynamics 25, 1133 (1993)

5. G. Della Gatta, M. J. Richardson, S. M. Sarge and S. Stølen, Pure and Applied Chemistry 78, 1455 (2006)

6. B. Legendre, D. Girolamo, P. Le Parlouer and B. Hay, Revue Française De Métrologie 1, 23 (2006)

7. F. Haloua, J.-N. Ponsard, G. Lartigue, B. Hay, C. Villermaux, E. Foulon, and M. Zaréa, International Journal of Thermal Sciences 55, 40 (2012)

8. F. Haloua, B. Hay, and E. Foulon, Journal of Thermal Analysis and Calorimetry 111, 985 (2013)

9. P. Schley, M. Beck, M. Uhrig, S.M. Sarge, J. Rauch, F. Haloua, J.-R. Filtz, B. Hay, M. Yakoubi, J. Escande, A. Benito, and P.L. Cremonesi, International Journal of Thermophysics 31, 665 (2010)

10. F. Haloua, B. Hay, and J.-R. Filtz, Journal of Thermal Analysis and Calorimetry 97, 673 (2009)

11. E. Calvet and H. Prat, Recent Progress in Microcalorimetry (Pergamon Press, Oxford, 1963), p. 177

12. R. Razouk, B. Hay and M. Himbert, Review of Scientific Instruments. 84, 094903 (2013)

13. G. van der Plaats, Thermochimica Acta 72, 77 (1984)

14. ISO IEC Guide 98-3, (2008)

15. S. Stølen and F. Grønvold, Thermochimica Acta 327, 1 (1999)

16. A. Dinsdale, CALPHAD 15, 317 (1991)

17. J. Ancsin, Metrologia 41, 198 (2004)

18. J. V. McAllen, American Institute of Physics 5, 371 (1982)

19. J. Tapping and T. P. Jones, Metrologia 25, 41 (1988)

20. C. Cagran, B. Wilthan, and G. Pottlacher, Thermochimica Acta 445, 104 (2006)

21. H. Landolt and R. Bornstein, Numerical Data and Functional Relationships in Science and Technology 19, 30 (2007) 